\title{
From Resilient to Thriving: Policy Recommendations to Support Health and Well-being in the Arctic
}

\author{
Katie Cueva, ${ }^{1}$ Elizabeth Rink, ${ }^{2}$ Josée G. Lavoie, ${ }^{3}$ Gwen Healey Akearok,${ }^{4}$ Sean Guistini, ${ }^{5}$ Nicole Kanayurak, \\ Jon Petter A. Stoor ${ }^{7}$ and Christina V.L. Larsen ${ }^{8}$
}

(Received 31 July 2020; accepted in revised form 19 May 2021)

\begin{abstract}
In 2018-19, eight Indigenous and non-Indigenous individuals from Canada, Greenland/Denmark, Sweden, and Alaska/United States came together to address research questions relevant to Arctic nations' shared challenges and opportunities. Our work incorporated critical, community-based perspectives on Arctic health and well-being and promoted strengths-based approaches developed in partnership with Arctic communities. In this article we describe the group's 16 action-oriented policy recommendations to support health and well-being in the Arctic in four thematic areas: 1) acknowledge and integrate Indigenous rights and knowledges, 2) implement meaningful action to address Indigenous determinants of health, 3) expand health-oriented monitoring and assessment programs, and 4) implement community-led, critical research approaches that focus on partnerships, reciprocity, adherence to ethical guidelines, and funding community-based research. Our recommendations are actionable guidelines for policy and research aimed at reducing inequities, supporting Indigenous expertise and existing knowledge, and promoting thriving communities in the Arctic.
\end{abstract}

Key words: circumpolar; Indigenous; community; strength; policy; health; well-being

RÉSUMÉ. En 2018-2019, huit personnes autochtones et non autochtones du Canada, du Groenland (Danemark), de la Suède et de l'Alaska (États-Unis) se sont réunies pour discuter de questions de recherche se rapportant aux défis et aux occasions se présentant dans les nations de l'Arctique. Notre travail a tenu compte de perspectives critiques et communautaires sur la santé et le bien-être dans l'Arctique, en plus de promouvoir des approches fondées sur les points forts, approches élaborées de concert avec des collectivités de l'Arctique. Dans cet article, nous décrivons les 16 recommandations de politiques axées sur des actions formulées par le groupe. Ces recommandations ont pour but de favoriser la santé et le bien-être dans l'Arctique et portent sur quatre grands thèmes : 1) reconnaître et intégrer les droits et les connaissances des Autochtones; 2) mettre en œuvre des actions significatives tenant compte des déterminants de la santé des Autochtones; 3) élargir les programmes d'évaluation et de surveillance axés sur la santé; et 4) adopter des démarches de recherche critiques dirigées par les collectivités mettant l'accent sur les partenariats, la réciprocité, le respect des lignes directrices en matière d'éthique et le financement de travaux de recherche communautaire. Nos recommandations prennent la forme de lignes directrices réalisables pour donner lieu à des politiques et des recherches visant à réduire les inégalités, à appuyer l'expertise et les connaissances actuelles des Autochtones, et à promouvoir des collectivités florissantes dans l'Arctique.

Mots clés : circumpolaire; Autochtone; collectivité; points forts; politiques; santé; bien-être

Traduit pour la revue Arctic par Nicole Giguère.

\footnotetext{
${ }^{1}$ Institute of Social and Economic Research, University of Alaska Anchorage, 3211 Providence Dr., Anchorage, Alaska 99508, USA; kcueva@alaska.edu

${ }^{2}$ Department of Health and Human Development, Montana State University, Bozeman, Montana 59717, USA

${ }^{3}$ Ongomiizwin Research, Department of Community Health Sciences, University of Manitoba (Bannatyne campus), Winnipeg, Manitoba R3E 0W3, Canada

${ }^{4}$ Qaujigiartiit Health Research Centre, Iqaluit, Nunavut XOA 0H0, Canada

${ }^{5}$ Nunavut Arctic College, PO Box 600, Iqaluit, Nunavut XOA 0H0, Canada

${ }^{6}$ North Slope Borough Department of Wildlife Management, Utqiagvik, Alaska 99723, USA

${ }^{7}$ Department of Epidemiology and Global Health, Umeå University, 90187 Umeå, Sweden

${ }^{8}$ National Institute of Public Health, University of Southern Denmark, 1455 Copenhagen K, Denmark and Greenland Centre for Health Research, University of Greenland, 3900 Nuuk, Greenland

(C) The Arctic Institute of North America
} 


\section{BACKGROUND}

In 2018-19, eight Indigenous and non-Indigenous individuals with strong connections to the circumpolar North participated in the Fulbright Arctic Initiative (FAI), cohort II, Resilient Communities group. The group included members from Canada, Greenland/Denmark, Sweden, and Alaska/United States. The group was brought together for a series of three week-long seminar meetings and individual research exchanges in Canada, Finland, and the United States. The task set before the group was to explore evidence, perspectives, and policies related to resilience in Arctic communities.

The FAI is a part of the Fulbright Scholar Program. The first cohort of the FAI was launched in 2015 during the U.S. chairmanship of the Arctic Council. Formally established in 1996, the Arctic Council is the leading intergovernmental forum promoting cooperation, coordination, and interaction among the Arctic states, Arctic Indigenous Peoples, and other Arctic inhabitants on common Arctic issues, in particular on issues of sustainable development and environmental protection in the Arctic (AC, 2021).

The FAI aims to bring together scholars from all eight member states of the Arctic Council (i.e., Canada, Finland, Greenland/Denmark, Iceland, Russia, Sweden, Norway, and the United States) to develop research and policy priorities for the Arctic. The intention of FAI is to create international interdisciplinary scientific collaboration among participants to enhance problem solving, advance research, and provide policy recommendations in the Arctic (Virginia et al., 2016). As part of the initiative, fellows addressed public policy research questions relevant to the shared challenges and opportunities of Arctic nations.

The recommendations presented here are a collaborative synthesis of our unique lived and professional experiences to support research on health and well-being in the circumpolar North, respectful and mindful of the communities in which we both reside and work and have done so for decades. Our perspectives were thus informed by decades of research, professional expertise, and experiences of living in and collaborating with thriving Arctic communities. Our recommendations also build on the work conducted by the first Fulbright Arctic Initiative (2016-17) (Virginia et al., 2016). This article describes the final policy recommendations of the FAI II Resilient Communities group, which are intended for policy and decision makers as well as researchers in the Arctic focused on improving the health and well-being of Arctic peoples.

FAI scholars have heard Arctic communities repeatedly state that Arctic scholars and policy makers need to dig deeper into narratives on health and well-being in the Arctic to move past a focus on resilience and rather focus on understanding and supporting what makes Arctic communities thrive (Healey Akearok et al., 2019). Historically, health research in the Arctic has primarily been focused on documenting disease and risk factors using a narrow set of deficit-oriented epidemiologic indicators (i.e., prevalence of diseases). This type of research might inform the design and resource requirements of a health system but does not adequately capture the complexities of community health and well-being and fails to highlight pathways that support community well-being. Research on Arctic communities' contexts, strengths, and continued expressions of well-being has received insufficient attention. Consequently, the fellows developed and published a conceptual framework to encourage investigation into the contextual factors that support circumpolar communities to thrive (Cueva et al., 2021).

\section{METHODS}

As part of the Fulbright experience, scholars came together to develop policy recommendations to support health and well-being in the Arctic. The scholars held in-person and online collaborative meetings during the 18-month-long programme, conducted a circumpolar sharing circle (Healey Akearok et al., 2019), facilitated interdisciplinary workshops and roundtables in Alaska, Denmark, Greenland, Iceland, and Washington D.C., completed circumpolar literature reviews, and implemented individual research projects focused on the circumpolar North. Throughout these activities, the scholars listened to a diversity of voices sharing perspectives on health in the North, including Arctic community members, organizational representatives, health care providers, researchers, policy makers, youth, and Elders.

A short summary of our recommendations has been published in a policy brief produced by the Fulbright Arctic Initiative. The purpose of this paper is to share the rationale for the recommendations and provide guidance towards implementation.

The recommendations outlined in this paper both validate and expand upon the Fulbright Arctic Initiative Cohort I (Virginia et al., 2016) and move the field of health and wellness research in the Arctic forward. The Arctic Health Declaration (AC, 2011:2) by the Arctic Council signed by seven of the eight Arctic states, asserts:

We declare our intention to:

- Strengthen circumpolar collaboration in health promotion, disease surveillance, and culturally appropriate health care delivery,

- Increase circumpolar sharing of knowledge regarding common health opportunities and challenges such as lifestyle related wellbeing, health, and ill-health,

- Continue empowerment of Indigenous Peoples and other Arctic residents through health promotion and disease prevention, including increased participation in health research by Indigenous Peoples and other Arctic residents, 
- Enhance mental health and prevention of substance abuse and suicides through exchange of experience and good practices,

- Extend use of e-health applications including telemedicine as a means of improving health and health care,

- Continue efforts to improve and sustain long-term observation, monitoring, and surveillance of diseases and changes in Arctic health, including circumpolar comparative studies to identify lessons learned, best practices, and innovative models and approaches for improving health,

- Increase circumpolar cooperation on assessing, mitigating, and adapting to the health impacts of climate change and environmental impacts on health,

- Enhance cooperation regarding health promotion and research with relevant Arctic Council observer organizations, regional bodies, and the World Health Organization.

Our goal as FAI II scholars was to advance the recommendations of FAI I to facilitate action-policy implementation with the Arctic Council and national governments among the eight Arctic member states.

\section{ARCTIC HEALTH AND WELL-BEING POLICY RECOMMENDATIONS}

Our 16 policy recommendations focus on four thematic areas: 1) acknowledge and integrate Indigenous rights and knowledges, 2) implement meaningful action to address Indigenous determinants of health, 3) expand healthoriented monitoring and assessment programs, and 4) implement community-led critical research approaches. Recommendations associated with each theme are designed to support current and future Arctic communities and policy makers to develop pathways to address health inequities and thrive.

Our recommendations incorporate critical, communitybased perspectives on Arctic health and well-being and privilege the perspectives of Indigenous Peoples in the Arctic. Current research suggests that community-led critical research approaches with Indigenous communities include 1) community-based participatory research methods that foster equity between Indigenous and academic partners, 2) an effort to bridge the cultural and worldview gaps between Indigenous knowledge and Western science through engaged conversations between Indigenous community members and scientists, 3) engagement to address the ethics of research with Indigenous communities and local control of research studies conducted with Indigenous Peoples, on their lands and in their water systems, and 4) a need to attend to the ethical and cultural dimensions of generating research outcomes that Indigenous communities can actually apply to their lived experiences (Nickels and Knotsch, 2011;
Sámediggi, 2018; Wallerstein et al., 2018; Matthews, 2019; Qaujigiartiit Health Research Centre, 2019; Rasmus et al., 2020; Lavoie et al., in press).

The work promotes strengths-based approaches developed in partnership with Arctic communities in Canada, Alaska, Sapmi, and Greenland. These approaches transform deficit-based approaches to a position of asset and strength (Maton and Hrabowski, 2004). The 16 recommendations are described in more detail and discussed below according to the four thematic areas.

\section{Acknowledge and Integrate Indigenous Rights and Knowledges}

The Arctic is the home of Indigenous Peoples with recognized Indigenous rights under international treaties and covenants (Toebes, 1999; Lavoie et al., 2021a). Despite these provisions, the Arctic has become a contested space in dominant discourses, with an increasing number of Arctic and non-Arctic states and stakeholders competing for a say in governance over economic and political interests in the circumpolar North (Johannsdottir and Cook, 2017; Keil and Knecht, 2017). Throughout circumpolar countries, Indigenous Peoples have focused self-determination activities on securing their stewardship over sustainable resource development in their territories. International interests in the Arctic have largely focused on access to resources and have side-stepped international covenants on Indigenous rights (UN, 2011). Dominant discourses have ignored the thriving Indigenous communities that exist across the Arctic, the thousands of years of Indigenous knowledge and local knowledge that live in these communities and their relevance to discussions of sustainable development in the Arctic, and the needs of Arctic communities that, in our view, must supersede other interests.

To acknowledge and integrate Indigenous ways and knowledges we recommend:

- that all countries participating in Arctic research implement the United Nations Declaration on the Rights of Indigenous Peoples (UNDRIP),

- that Indigenous knowledges, expertise, and community perspectives are integrated effectively into policy and health system design in local, regional, state, federal, and international levels of governance,

- to change Indigenous representation on the Arctic Council from that of Permanent Participants to the same status as states, in all consensus-building processes, and

- that funding is allocated for organizations working to advance the rights of Arctic peoples.

We assert that Indigenous Peoples' rights to self-determination and sovereignty must be fully acknowledged, with Indigenous knowledges guiding the creation, implementation, and continual assessment and improvement of health and well-being in the Arctic. As local communities and populations must be involved, 
the specific definitions and contributions of Indigenous knowledges and the actualization of Indigenous rights will differ from one country to the next and among Indigenous nations. Nevertheless, circumpolar nations should begin or expand commitments to recognize Indigenous knowledges and rights, both to reduce health inequities and adhere to obligations outlined in the UNDRIP.

UNDRIP articulates the inalienable rights of Indigenous Peoples "to the enjoyment of the highest attainable standard of physical and mental health." Article 24 specifically outlines the right to health; states who have signed onto UNDRIP are thus obligated to guarantee that Indigenous Peoples receive the same services accessible to all citizens without discrimination. Signatory states must also guarantee access to services grounded in Indigenous cultures, medicines, and practices and must address determinants of health negatively impacting Indigenous health, at least to the same extent as is possible at the national level.

The Arctic Council has grown over its 20 years as the Circumpolar Council, and Permanent Participants continue to collaborate with little funding and human resources (AC, 2016). Meaningful engagement is a priority of the Permanent Participants of the Arctic Council and the Arctic communities they represent (PAME, 2017). The category of Permanent Participants of the Arctic Council was established in the founding declaration - the Ottawa Declaration - of the Arctic Council in 1996 (AC, 2016). The intent in the Ottawa Declaration was for Permanent Participants to actively participate and be fully consulted while decisions were to be made by consensus of all Arctic Council members including Permanent Participants (AC, 2016). Given the growth of the Arctic Council and recognition of the UNDRIP, we recommend that the Arctic Council expand the role of the Permanent Participants to the same status as states to support the health and wellbeing of Arctic Indigenous Peoples.

\section{Implement Meaningful Action to Address Indigenous Determinants of Health}

Personal, social, economic or environmental factors determine the health status of individuals and populations (WHO, 2021). These health determinants impact populations through micro- (interpersonal), meso- (societal) and macro-(system) levels of influence. Determinants of health may include but are not limited to (Bambra et al., 2010; Chatwood et al., 2012; Driscoll et al., 2013):

- Income and social status - Higher income and social status are linked to better health. The greater the gap between the richest and poorest people in a society, the greater the differences in health.

- Education - Low education levels are linked with poor health, more stress, and lower self-confidence.
- Physical environment - Safe water and clean air, healthy workplaces, safe houses, communities, and roads all contribute to good health.

- Occupation - People who are employed are healthier, particularly those who have more control over their working conditions.

- Social support networks - Greater support from families, friends, and communities is linked to better health.

- Culture - Customs, traditions, and the beliefs of the family and community all impact health.

- Genetics - Inheritance plays a part in determining lifespan, healthiness, and the likelihood of developing certain illnesses.

- Personal behavior and coping skills - Nutritious eating, keeping active, staying tobacco- and alcohol-free, and dealing well with life's stresses and challenges all impact health.

- Historical trauma - Historical trauma linked to the colonization of Indigenous Peoples has disrupted traditional cultural practices, beliefs, and food systems that promoted health.

- Health services - Access and use of services that prevent and treat disease influence health.

- Sex, gender and age - Individuals of different genders suffer from different types of diseases at different ages.

An emerging literature on Indigenous determinants of health is drawing attention to the importance of selfdetermination, language, the expression of Indigenous knowledges, and the connection between the land and spirituality (Greenwood and de Leeuw, 2012; MacDonald et al., 2013; Greenwood et al., 2015; Tagalik, 2015; Healey Akearok, 2018; Redvers, 2020).

To implement meaningful action to address Indigenous determinants of health we recommend:

- beginning with what Indigenous and Arctic communities are already doing to support health and well-being, then commit to supporting their initiatives and priorities,

- recognizing and enhancing Indigenous leadership in communities, the academy, health systems, and governance structures,

- creating and supporting pathways for community practices, perspectives, and priorities on determinants of health to be integrated in health care systems and governments, and

- seeking the perspectives of underrepresented groups, such as young people and the elderly, and integrate these into health services and systems.

In the realm of public health, improving health outcomes in populations requires addressing the root causes of illness and the positive protective factors that contribute to wellbeing. Addressing determinants of health that are identified by Arctic communities as critical is essential to the advancement of health and well-being in the Arctic. Many 
locally driven organizations and service providers across the Arctic have developed interventions such as programs and services that originate from local perspectives and build on the strengths of Arctic communities and peoples. Such approaches address health determinants through multiple pathways. These pathways may include the revitalization of Indigenous languages, supporting youth leadership, or the promotion of local food systems (Allen et al., 2014; McMillan, 2015; Watson, 2017; Cueva et al., 2018, 2020; Kenny et al., 2018; Redvers et al., 2019).

Communities innovate to meet emerging demands. These innovations are rarely published in peer-reviewed literature or noticed by dominant cultural structures and organizations. Still today, policies and programs designed to support communities are informed by urbancentric evidence and mainstream values (Lavoie et al., 2016, 2021b). This disconnect perpetuates problematic perceptions that Indigenous communities are "in need" of assistance, where, in fact, outside assistance might be experienced as interference with locally informed solutions. It is imperative that policy makers, program planners, and researchers engage communities to learn of and from local initiatives and innovations and ensure that outside support builds on existing local priorities and expertise.

Although Indigenous knowledges can inform and shape culturally relevant, effective, and sustainable policies, Indigenous Peoples are rarely provided with such opportunities. Further, circumpolar Indigenous communities have been largely excluded from participation in international and national discussions that can directly impact their health and well-being. Indigenous Peoples' presence and participation in international fora are constrained by limited access to invitations, as well as resources to mobilize, plan interventions, and attend these meetings. Indigenous rights can only be operationalized if Indigenous participation is privileged and resourced appropriately.

\section{Expand Health-Oriented Monitoring and Assessment Programs}

The most common narratives on health and wellbeing in the circumpolar North focus on a small scope of epidemiologic indicators (Bjerregaard et al., 2004; Sherry, 2004; Hansen et al., 2010; Young, 2012; AMAP, 2015; Redvers et al., 2015). While this work is valuable, there is much that lies below the surface of indicators such as mortality, incidence, and prevalence rates of specific diseases. To support thriving communities in the circumpolar North, the academic community needs to delve deeper to investigate strengths-based factors that promote a culture of health (Cueva et al., 2021).

To expand health-oriented monitoring and assessment programs we recommend:

- establishing health and well-being monitoring programs in Arctic contexts that follow Indigenous ethical guidelines and build on Indigenous knowledges to track community-defined measures of health and well-being over time,

- creating and expanding approaches to the assessment of Arctic peoples' health and well-being that include integrated mixed methods and innovative research in small populations,

- implementing and evaluating community-driven and evidence-based strategies to address health inequities in Arctic communities,

- allocating funding for information sharing between communities throughout the Arctic.

To address health and well-being and the inequities in the Arctic in a meaningful way, we recommend that monitoring programs for health and well-being are in place. In some Arctic regions, monitoring systems need to be established, whereas in other regions they need to be strengthened and coordinated among different agencies and sectors through collaboration. Further, we argue that such monitoring programs must go beyond the classic epidemiological indicators that often dominate the discussions on health in the Arctic to ensure the inclusion of new and innovative approaches to assess Arctic peoples' health and well-being.

Indicators are the foundation stones of monitoring and assessment programs and we argue that researchers, community members, and policy makers must innovatively collaborate in developing indicators to make sure that these are community-driven, relevant, and meaningful in their context. Identifying relevant indicators for thriving communities through a circumpolar sharing circle is an example of an innovative method that is also in line with Indigenous science and ways of sharing information among Arctic peoples (Healey Akearok et al., 2019). By exploring more culturally relevant methods in epidemiological research, indicators for health and well-being in the Arctic will be more likely to mirror the holistic understanding of health in many Indigenous cultures across the circumpolar area.

We recommend that community-driven (and evidencebased) strategies to address health inequities in Arctic communities already in place receive funding and resources to enable proper implementation and evaluation. Often new research and strategies are put into place without connection to existing programs and experiences. This issue is typically caused by the lack of community engagement before, during, and after implementation. Evidence generated from outside circumpolar communities is often privileged and resourced, whereas local community-based strategies, even when shown to be effective, are rarely used to inform larger-scale innovations. Developing systems that prioritize local knowledge and the translation of this knowledge to community members and policy makers across circumpolar countries are critical to advancing wellness in the North.

External intrusion and sustained cultural repression in Arctic Indigenous communities has interrupted the transmission of local knowledge. Indigenous Peoples of the 
Arctic have a right to assess and contextualize their own social-cultural vitality and well-being (UN, 2011; Ritsema et al., 2015; Poto, 2017). Facilitating Indigenous Peoples' actualization of this right advances Indigenous selfdetermination and allows for local, regional, national, and international decision makers to make informed decisions founded on Indigenous epistemologies, which often vary immensely from Western epistemologies (Thayer-Bacon, 2003; Chilisa, 2012). So many strengths and challenges are shared across the Arctic, and research as well as policy must ensure the sharing of information about successful programs and experiences to promote health and well-being across communities within regions as well as throughout the circumpolar world.

\section{Implement Community-Led Critical Research Approaches}

Increasing attention on the Arctic has led to an increase in Arctic research on health and well-being, including health research in Arctic Indigenous communities. A growing segment of the research community is focused on explaining and understanding Indigenous knowledges and ways of knowing. Researchers have become increasingly aware that Indigenous knowledges must be recognized, recorded, and shared in ways that are unique to, and shaped by, the communities and individuals who are holders of this knowledge (ACUNS, 2003; ITK and NRI, 2007; First Nations, Metis, and Inuit Health Research Strategic Planning Committee, 2015; Mearns, 2017; Healey Akearok, 2018).

Community-led critical research approaches focus on research that is community-centered, supports co-learning and co-leadership among community members and researchers, and is initiated and supported by the community. Community-led critical research approaches ensure both adherence to community ethics protocols and that data and subsequent analyses accurately reflect the lived realities of Arctic peoples. A recent circumpolar review of ethical guidelines suggests that only Canada and the United States have developed guidelines and processes that respect the need to engage Indigenous communities in the creation and co-creation of knowledge (Lavoie et al., in press).

To implement community-led critical research approaches we recommend:

- ensuring equitable and reciprocal partnerships between Arctic communities, key stakeholders, and researchers throughout the research process from the identification of priorities to research questions, data collection, data analysis, and sharing of findings,

- committing financial and political support for community-led critical research approaches, including designated funding mechanisms,

- enhancing reciprocity (i.e., direct benefits for both researchers and communities) within research as negotiated by communities, key stakeholders, and researchers, and
- adhering to ethical guidelines for research in the Arctic where guidelines exist, and support the creation and promotion of ethical guidelines for research where they have not yet been developed. These guidelines and processes should be developed in partnership with, and be endorsed by, Arctic Indigenous communities. Guidelines may require multiple levels of review, including national, regional, and community-based ethics review boards.

Our recommendations are essential for ensuring that research conducted in the circumpolar context is an asset to Indigenous communities and built on the local knowledge, expertise, and paradigms of these communities. Health research with Indigenous circumpolar communities most often involves small, remote populations, which creates opportunities for innovative approaches to enhance scientifically rigorous health research (Allen et al., 2018). More recently, there is an increasing call for communitydriven research that joins Indigenous science with Western science (Dickerson et al., 2020). This integration of diverse knowledge systems creates the context to move forward the field of scientific inquiry with Indigenous communities.

\section{CONCLUSION}

In this paper we have recommended action for research and policy in the Arctic within four thematic areas to support current and future Arctic community members and policy makers to develop pathways to address health inequities and thrive. In our work, the research topics, the methods, and the authors are from or have an established history of engagement and knowledge co-development with northern communities. Therefore, our recommendations are presented through the lens of scholars with this history and life experience. However, the recommendations presented here are not representative of the entire Arctic population on the topic of future policy directions, as the North is home to numerous heterogeneous populations and perspectives. We hope that future policy research applies and expands the recommendations shared in this manuscript and shares divergent perspectives from the Indigenous Arctic.

\section{ACKNOWLEDGEMENTS}

First, we wish to acknowledge the Arctic communities where we have lived or worked, which have and continue to inspire us to effect change for present and future generations. We also wish to acknowledge the financial support of the Fulbright Foundation for supporting individual and collective research undertaken through the Fulbright Arctic Initiative 2018-19. This project was supported by a Fulbright Program grant sponsored by the Bureau of Educational and Cultural Affairs of the United States Department of State and administered by the Institute of International Education. 


\section{REFERENCES}

AC (Arctic Council). 2011. The Arctic health declaration. Tromsø: Arctic Council Secretariat. http://hdl.handle.net/11374/1058

- 2016. Arctic resilience report. Carson, M., and Peterson, G., eds. Stockholm: Stockholm Environment Institute and Stockholm Resilience Centre.

https://oaarchive.arctic-council.org/handle/11374/1838

- 2021. About the Arctic Council. Tromsø: Arctic Council Secretariat.

https://arctic-council.org/en/about

ACUNS (Association of Canadian Universities for Northern Studies). 2003. Ethical principles for the conduct of research in the North. Ottawa: ACUNS.

https://acuns.ca/wp-content/uploads/2010/09/ EthicsEnglishmarch2003.pdf

Allen, J., Hopper, K., Wexler, L., Kral, M., Rasmus, S., and Nystad, K. 2014. Mapping resilience pathways of Indigenous youth in five circumpolar communities. Transcultural Psychiatry 51(5):601-631.

https://doi.org/10.1177/1363461513497232

Allen, J., Rasmus, S.M., Fok, C.C.T., Charles, B., Henry, D., and Qungasvik, Team. 2018. Multi-level cultural intervention for the prevention of suicide and alcohol use risk with Alaska Native youth: A nonrandomized comparison of treatment intensity. Prevention Science19(2):174-185.

https://doi.org/10.1007/s11121-017-0798-9

AMAP (Arctic Monitoring and Assessment Program). 2015. AMAP Assessment 2015: Human health in the Arctic. Oslo: AMAP.

https://www.amap.no/documents/doc/amap-assessment-2015human-health-in-the-arctic/1346

Bambra, C., Gibson, M., Sowden, A., Wright, K., Whitehead, M., and Petticrew, M. 2010. Tackling the wider social determinants of health and health inequalities: Evidence from systematic reviews. Journal of Epidemiology \& Community Health 64(4):284-291.

https://doi.org/10.1136/jech.2008.082743

Bjerregaard, P., Young, T.K., Dewailly, E., and Ebbesson, S.O.E. 2004. Review Article: Indigenous health in the Arctic: An overview of the circumpolar Inuit population. Scandinavian Journal of Public Health 32(5):390-395.

https://doi.org/10.1080/14034940410028398

Chatwood, S., Bjerregaard, P., and Young, T.K. 2012. Global health-A circumpolar perspective. American Journal of Public Health 102(7):1246-1249. https://doi.org/10.2105/AJPH.2011.300584

Chilisa, B. 2012. Indigenous research methodologies, 1st ed. Thousand Oaks, California: SAGE Publications.

Cueva, K., Lovato, V., Nieto, T., Neault, N., Barlow, A., and Speakman, K. 2018. Increasing healthy food availability, purchasing, and consumption: Lessons learned from implementing a mobile grocery. Progress in Community Health Partnerships: Research, Education, and Action 12(1):65-72. https://doi.org/10.1353/cpr.2018.0007
Cueva, K., Speakman, K., Neault, N., Richards, J., Lovato, V., Parker, S., Carroll, D., Sundbo, A., and Barlow, A. 2020. Cultural connectedness as obesity prevention: Indigenous youth perspectives on Feast for the Future. Journal of Nutrition Education and Behavior 52(6):632-639.

https://doi.org/10.1016/j.jneb.2019.11.009

Cueva, K., Rink, E., Lavoie, J.G., Stoor, J.P.A., Healey Akearok, G., Gladun, E., and Larsen, C.V.L. 2021. Diving below the surface: A framework for Arctic health research to support thriving communities. Scandinavian Journal of Public Health. Published online 25 April 2021.

https://doi.org/10.1177/14034948211007694

Dickerson, D., Baldwin, J.A., Belcourt, A., Belone, L., Gittelsohn, J., Keawe'aimoku Kaholokula, J., Lowe, J., Patten, C.A., and Wallerstein, N. 2020. Encompassing cultural contexts within scientific research methodologies in the development of health promotion interventions. Prevention Science 21(1):33-42. https://doi.org/10.1007/s11121-018-0926-1

Driscoll, D.L., Dotterrer, B., and Brown, R.A., II. 2013. Assessing the social and physical determinants of circumpolar population health. International Journal of Circumpolar Health 72(1): 21400 .

https://doi.org/10.3402/ijch.v72i0.21400

Greenwood, M.L., and de Leeuw, S.N. 2012. Social determinants of health and the future well-being of Aboriginal children in Canada. Paediatrics \& Child Health 17(7):381 - 384.

https://www.ncbi.nlm.nih.gov/pmc/articles/PMC3448539/

Greenwood, M.L., de Leeuw, S., Lindsay, N.M., and Reading, C., eds. 2015. Determinants of Indigenous Peoples' health in Canada: Beyond the social. Toronto, Ontario: Canadian Scholars' Press.

Hansen, K.L., Melhus, M., and Lund, E. 2010. Ethnicity, selfreported health, discrimination and socio-economic status: A study of Sami and non-Sami Norwegian populations. International Journal of Circumpolar Health 69(2):111 - 128. https://doi.org/10.3402/ijch.v69i2.17438

Healey Akearok, G. 2018. Exploring the development of a health care model based on Inuit wellness concepts as part of self-determination and improving wellness in northern communities. In: Arya, A.N., and Piggott, T., eds. Underserved: Health determinants of Indigenous, inner-city, and migrant populations in Canada. Toronto, Ontario: Canadian Scholars. 92-104.

Healey Akearok, G., Cueva, K., Stoor, J.P.A., Larsen, C.V.L., Rink, E., Kanayurak, N., Emelyanova, A., and Hiratsuka, V.Y. 2019. Exploring the term "resilience" in Arctic health and well-being using a sharing circle as a community-centered approach: Insights from a conference workshop. Social Sciences 8(2): 45. https://doi.org/10.3390/socsci8020045

ITK and NRI (Inuit Tapiriit Kanatami and Nunavut Research Institute). 2007. Negotiating research relationships with Inuit communities, A guide for researchers. Nickels, S., Shirley, J., and Laidler, G., eds. Ottawa: ITK; Iqaluit: NRI. https://www.itk.ca/negotiating-research-relationships-guide/ 
Johannsdottir, L., and Cook, D. 2017) Discourse analysis of the 2013-2016 Arctic Circle Assembly programmes. Polar Record 53(3):276-279.

https://doi.org/10.1017/S0032247417000109

Keil, K., and Knecht, S., eds. 2017. Governing Arctic change: Global perspectives. London: Palgrave Macmillan. https://doi.org/10.1057/978-1-137-50884-3

Kenny, T.-A., Fillion, M., Simpkin, S., Wesche, S.D., and Chan, H.M. 2018. Caribou (Rangifer tarandus) and Inuit nutrition security in Canada. EcoHealth 15(3):590-607. https://doi.org/10.1007/s10393-018-1348-z

Lavoie, J.G., Wong, S., Katz, A., and Sinclair, S. 2016. Opportunities and barriers to rural, remote and First Nation health services research in Canada: Comparing access to administrative claims data in Manitoba and British Columbia. Healthcare Policy 12(1):52-58 https://doi.org/10.12927/hcpol.2016.24775

Lavoie, J.G., Stoor, J.P., Rink, E., Cueva, K., Gladun, E., Larsen, C.V.L., Healey Akearok, G. and Kanayurak, N. 2021a. Historical foundations and contemporary expressions of a right to health care in circumpolar Indigenous contexts: A crossnational analysis. Elementa: Science of the Anthropocene 9(1): 00079/

https://doi.org/10.1525/elementa.2019.00079

Lavoie, J.G., Kornelsen, D., and Boyer, Y. 2021b. Rewriting health policy for the north: Patchy and southern-centric: Health policies for northern and Indigenous Canadians. In: Schiff, R., and Møller, R.S.R., eds. Health and healthcare in the Canadian North. Vancouver: UBC Press. 377-395.

Lavoie, J.G., Stoor, J.P., Rink, E., Cueva, K., Gladun, E., Larsen, C. V. L., Kanayurak, N. (2021). Indigenous engagement in health research in circumpolar countries: An analysis of existing ethical guidelines. International Indigenous Policy Journal, In press.

MacDonald, J.P., Ford, J.D., Cunsolo Willox, A., and Ross, N.A. 2013. A review of protective factors and causal mechanisms that enhance the mental health of Indigenous circumpolar youth. International Journal of Circumpolar Health 72(1): 21775.

https://doi.org/10.3402/ijch.v72i0.21775

Maton, K.I., and Hrabowski, F.A., III. 2004. Increasing the number of African American PhDs in the sciences and engineering: A strengths-based approach. American Psychologist 59(6): $547-556$. https://doi.org/10.1037/0003-066X.59.6.547

Matthews, R. 2019. Health ethics and Indigenous ethnocide. Bioethics 33(7):827-834 https://doi.org/10.1111/bioe.12610

McMillan, B. 2015. Educating for cultural survival in Nunavut: Why haven't we learned from the past? Paideusis 22(2):24-37. https://doi.org/10.7202/1071456ar
Mearns, R. 2017. Nunavut, Uqausivut, Piqqusivullu Najuqsittiarlavu (Caring for our land, language and culture): The use of land camps in Inuit knowledge renewal and research. MA thesis, Geography \& Environmental Studies, Carleton University, Ottawa, Ontario.

https://curve.carleton.ca/14db37c3-2a46-4485-ab90bd5a97c9efc1

Nickels, S., and Knotsch, C. 2011. Inuit perspectives on research ethics: The work of Inuit Nipingit. Études/Inuit/Studies 35 (1-2):57-81.

h t t p s://s earch.informit.org/doi/10.3316/ informit.601977958453543

First Nations, Metis, and Inuit Health Research Stategic Planning Committee. 2015. Framework for research engagement with First Nations, Metis and Inuit Peoples. Winnipeg: Faculty of Health Sciences, University of Manitoba.

https://umanitoba.ca/faculties/health_sciences/medicine/ media/UofM_Framework_Report_web.pdf

PAME (Protection of the Arctic Marine Environment). 2017. Meaningful engagement of Indigenous Peoples and communities in marine activities (MEMA): Part I report: Arctic Council and Indigenous engagement - A review.

https:/pame.is/document-library/resource-exploration-anddevelopment/meaningful-engagement-of-indigenous-peoplesand-local-communities-in-marine-activities-mema/416meaningful-engagement-of-indigenous-peoples-and-communities-in-marine-activities-mema-part-i-report/file

Poto, M.P. 2017. Participatory engagement and the empowerment of the Arctic Indigenous Peoples. Environmental Law Review 19(1):30-47.

https://doi.org/10.1177/1461452917691778

Qaujigiartiit Health Research Centre. 2019. Health research ethics checklist. Iqaluit: QHRC.

https://www.qhrc.ca/wp-content/uploads/2019/09/EthicsReview-Checklist-OCT-2019.pdf

Rasmus, S.M., Whitesell, N.R., Mousseau, A., and Allen, J. 2020. An intervention science to advance underrepresented perspectives and Indigenous self-determination in health. Prevention Science 21(1):83-92. https://doi.org/10.1007/s11121-019-01025-1

Redvers, J. 2020. “The land is a healer": Perspectives on land-based healing from Indigenous practitioners in northern Canada. International Journal of Indigenous Health 15(1):90-107. https://doi.org/10.32799/ijih.v15i1.34046

Redvers, J., Bjerregaard, P., Eriksen, H., Fanian, S., Healey, G., Hiratsuka, V., Jong, M., et al. 2015. A scoping review of Indigenous suicide prevention in circumpolar regions. International Journal of Circumpolar Health 74(1): 27509. https://doi.org/10.3402/ijch.v74.27509

Redvers, N., Marianayagam, J., and Blondin, B. 2019. Improving access to Indigenous medicine for patients in hospital-based settings: A challenge for health systems in northern Canada. International Journal of Circumpolar Health 78(2): 1589208. https://doi.org/10.1080/22423982.2019.1589208 
Ritsema, R., Dawson, J., Jorgensen, M., and Macdougall, B. 2015. "Steering our own ship?" An assessment of self-determination and self-governance for community development in Nunavut. The Northern Review 41:157-180. https://doi.org/10.22584/nr41.2015.007

Sámediggi. 2018. Proposal for ethical guidelines for Sámi health research and research on Sámi human biological material. Karasjok, Norway: The Sámediggi - The Sámi Parliament in Norway.

https://uit.no/Content/588355/cache=1534848132000/Proposal + for + Ethical + Guidelines + for $+\mathrm{S} \% \mathrm{C} 3 \% \mathrm{~A} 1 \mathrm{mi}+\mathrm{Health}+$ Researc $\mathrm{h}+$ and + Research + on $+\mathrm{S} \% \mathrm{C} 3 \% \mathrm{~A} 1 \mathrm{mi}+$ Human + Biological+Mat erial.pdf

Sherry, P. 2004. Health care delivery for Alaska Natives: A brief overview. International Journal of Circumpolar Health 63(sup2):54-62. https://doi.org/10.3402/ijch.v63i0.17786

Tagalik, S. 2015. Inuit knowledge systems, Elders, and determinants of health: Harmony, balance, and the role of holistic thinking. In: Greenwood, M.L., de Leeuw, S., Lindsay, N.M., and Reading, C., eds. Determinants of Indigenous Peoples' health in Canada: Beyond the social. Toronto, Ontario: Canadian Scholars' Press. 25-32.

Thayer-Bacon, B.J. 2003. Relational “(e)pistemologies.” New York: Peter Lang Inc., International Academic Publishers.

Toebes, B. 1999. Towards an improved understanding of the international human right to health. Human Rights Quarterly 21(3):661-679.

https://doi.org/10.1353/hrq.1999.0044
UN (United Nations). 2011. United Nations declaration on the rights of Indigenous Peoples.

https://www.worldcat.org/title/united-nations declaration-on-the-rights-of-indigenous-peoples/ oclc/946570775? page $=$ citation

Virginia, R.A., Sfraga, M., Arnborn, T., Chamberlain, L., Chatwood, S., Diş, A.T., Gjørv, G.H., et al. 2016. Briefing note: Fulbright Arctic Initiative: An innovative model for policy relevant research and public outreach. Arctic Yearbook. https://arcticyearbook.com/arctic-yearbook/2016/2016briefing-notes/201-fulbright-arctic-initiative-an-innovativemodel-for-policy-relevant-research-and-public-outreach

Wallerstein, N., Duran, B., Oetzel, J.G., and Minkler, M., eds. 2018. Community-based participatory research for health: Advancing social and health equity, 3rd ed. San Francisco, California: Jossey-Bass.

Watson, M.K. 2017. Nuutauniq (Moves in Inuit Life): Arctic transformations and the politics of urban Inuit mobility. American Review of Canadian Studies 47(2):189-205. https://doi.org/10.1080/02722011.2017.1333559

WHO (World Health Organization). 2021. Health determinants. https://www.euro.who.int/en/health-topics/healthdeterminants/social-determinants/social-determinants

Young, T.K., ed. 2012. Circumpolar health atlas. Toronto, Ontario: University of Toronto Press. https://doi.org/10.3138/9781442660908 